\title{
PENGEMBANGAN WISATA HIU PAUS BERBASIS IOT (INTERNET OF THINGS) MELALUI SIARAN LANGSUNG JELAJAH VIRTUAL HIU PAUS DI ALAM LIAR DI PANTAI DESA BOTUBARANI, KABILA BONE, BONE BOLANGO, GORONTALO
}

\author{
Mahardika Rizqi Himawan ${ }^{1,2^{*}}$, Sukirman Dj Tilahunga ${ }^{2,3}$, Eni Hidayati ${ }^{4}$, Nurliah ${ }^{1}$, Fahri Amar $^{5}$, \\ Casandra Tania ${ }^{6}$,
}

${ }^{1}$ Program Studi IImu Kelautan, Fakultas Pertanian, Universitas Mataram, ${ }^{2}$ Yayasan Ekonomi dan Keanekaragaman Hayati Laut Indonesia, 'Dinas Pariwisata Kabupaten Bone Bolango, Gorontalo,

${ }^{4}$ Program Studi Kehutanan, Fakultas Pertanian, Universitas Mataram, ${ }^{5}$ Kelompok Masyarakat Konservasi ORCA Desa Botubarani, Bone Bolango, ${ }^{6}$ Partnerships in Environmental Management for the Seas of East Asia

*Jalan Pendidikan No. 37, Kota Mataram, Indonesia

*Alamat korespondensi : mahardika@unram.ac.id

\section{Keyword : Abstrak :}

hiu paus, Hiu paus (Rhincodon typus) merupakan spesies ikan terbesar di dunia yang wisata, tidak bersifat agresif bagi manusia sehingga menjadi ikon wisata yang diminati. siaran Keberadaan hiu paus menjadi magnet wisata dan mengubah Desa Botubarani langsung, dari desa nelayan biasa menjadi desa wisata yang ramai. Pandemi Covid19 virtual, bawah air menjadi pukulan yang telak bagi pariwisata hiu paus di pantai Desa Botubarani. Wisatawan yang berkurang sangat drastis tidak hanya menghilangkan pendapatan wisata namun juga aktivitas pemantauan hiu paus turut terhenti. Rintisan Normal Baru pemerintah menjadi harapan kembalinya gairah pariwisata hiu paus di pantai Desa Botubarani. Desa Inovasi Botubarani mengembangkan siaran langsung jelajah virtual bawah air dengan objek hiu paus secara berkala di alam liar. Pengembangan ini adalah yang pertama di indonesia karena belum pernah dilakukan sebelumnya. Pemanfaatan televisi sirkuit tertutup atau closed circuit television (CCTV) bawah air yang dapat diakses di darat dan terintegrasi dengan internet memungkinkan hiu paus di Pantai Botubarani dapat dinikmati oleh siapapun dan dimanapun. Desa dan masyarakat di Pantai Botubarani dapat menerima masukan dari perkembangan wisata yang berlangsung dari wisatawan yang datang maupun secara virtual. Wisatawan juga mungkin akan tertarik untuk datang setelah melihat siaran langsung hiu paus di pantai Desa Botubarani. Perekaman video secara langsung hiu paus juga dapat dimanfaatkan oleh pihak intelektual, pemerintah dan industri sebagai bagian dari kolaborasi triple helix. 
Panduan Sitasi (APPA $7^{\text {th }}$ edition) :

Himawan, M. R., Tilahunga, S. D., Hidayati, E., Nurliah, Amar, F., \& Tania, C. (2022). Pengembangan Wisata Hiu Paus Berbasis lot (Internet Of Things) Melalui Siaran Langsung Jelajah Virtual Hiu Paus Di Alam Liar Di Pantai Desa Botubarani, Kabila Bone, Bone Bolango, Gorontalo. Jurnal Pengabdian Perikanan Indonesia, 2(1), 51-56. https://doi.org/10.29303/jppi.v2i1.500.

\section{PENDAHULUAN}

Hiu paus (Rhincodon typus) (Smith 1829) merupakan spesies ikan terbesar di dunia (Compagno 2001) yang dilindungi secara penuh melalui Keputusan Menteri Kelautan dan Perikanan RI nomor 18 Tahun 2013. Habitat Hiu paus yang terbentang pada perairan tropis hingga suptropis (Colman 1997), membuat spesies ini cukup mudah ditemukan di perairan Indonesia (Himawan et al., 2015). Beberapa daerah dengan kemunculan teratur setiap tahunnya adalah di Perairan Teluk Cenderawasih Papua, Talisayan Kalimantan Timur, Probolinggo Jawa Timur dan Botubarani Gorontalo.

Hiu paus di Perairan Botubarani, Kecamatan Kabila Bone, Kabupaten Bone Bolango, Provinsi Gorontalo adalah salah satu kawasan perairan dimana Hiu paus diduga muncul setiap hari akibat pemberian makan berupa kepala dan kulit udang vaname (Litopenaeus vannamei) melalui aktivitas wisata. Kemunculan Hiu paus di perairan Gorontalo sendiri menurut masyarakat nelayan beberapa kali muncul saat menjaring Ikan Nike (Awaous melancephalus). Perilaku beberapa individu yang selalu muncul tersebut telah beberapa kali dilakukan pengamatan dan pendataan secara berkala, untuk mengetahui apakah Hiu Paus tersebut akan tetap bertahan di Perairan Botubarani dalam waktu yang lama. Selain pengamatan terhadap perilaku, telah dilakukan juga pemasangan penanda akustik pada individu Hiu paus untuk menghasilkan data keberadaan individu tersebut di Perairan Botubarani setiap harinya. Dengan pemasangan penanda akustik tersebut, dapat diketahui apakah perilaku pemberian makan mempengaruhi pola pergerakan Hiu paus di Perairan Botubarani. Mengingat, Hiu Paus secara alami adalah spesies ikan bermigrasi yang berpindah dari satu tempat ke tempat lain untuk mencari makan. Tahapan menuju penerbitan kebijakan untuk penetapan kawasan perairan tersebut menjadi kawasan konservasi dan pengaturan aktivitas wisata selanjutnya dapat dirumuskan melalui hasil penelitian tersebut.

Tim pemantau hiu paus Gorontalo terbentuk di Tahun 2016. Kegiatan dari tim yang terbentuk tersebut adalah memantau kemunculan individu Hiu Paus di Perairan Botubarani. Selain itu, tim juga sekaligus melakukan pendataan, pengawasan dan pengaturan aktivitas wisata yang lebih sistematis dan sesuai dengan aturan berinteraksi yang berlaku di Indonesia.

Hanya beberapa ekor hiu paus yang berenang-renang di permukaan perairan, namun ribuan orang rela berdatangan dari berbagai daerah dan mengantri untuk dapat melihat dengan dekat. Hiu paus sebagai hewan yang tergolong tidak mudah untuk ditemui di wilayah perairan Indonesia, sangat memunculkan rasa penasaran orang untuk melihat secara langsung. Hiu paus memiliki tubuh yang sangat besar namun cenderung tidak berbahaya bagi manusia. Ikan ini tidak memiliki struktur gigi tajam seperti hiu lain, seperti hiu putih atau hiu banteng. Hiu paus juga tanpa risau berenang sangat dekat dengan manusia. Manusia dengan ukuran yang lebih kecil dibandingkan dengan hiu paus, sepertinya bukan mencadi ancaman bagi hewan ini. Karakter-karakter yang dimiliki hiu paus membuat hampir semua orang ingin melihatnya.

Banyaknya foto dan video yang bertebaran di sosial media mengenai aktivitas wisata hiu paus di Botubarani membuat orang-orang mulai merencanakan perjalanan ke Gorontalo. Cerita dan 
tayangan televisi mengenai serunya melihat dan berenang dengan hiu paus secara sangat dekat dari mereka yang telah berkunjung terus mempengaruhi orang untuk turut merasakannya. Tak hanya masyarakat lokal, wisatawan-wisatawan asing-pun mengetahui hal ini dari berbagai sumber yang sama. Sehingga, mereka menjadikan Pantai Botubarani sebagai destinasi wajib untuk dikunjungi ketika melakukan perjalanan wisata di Sulawesi.

Nelayan Desa Botubarani mulai beralih profesi menjadi pengantar wisata. Wisata hiu paus Pantai Botubarani dikelola sepenuhnya oleh masyarakat setempat melalui Pemerintah Desa, dengan dukungan dari Pemerintah Kabupaten dan Provinsi. Aturan-aturan yang berkenaan dengan biaya kunjungan/tiket bagi wisatawan ditetapkan melalui rapat desa.

Namun, pandemic covid19 merubah alur perkembangan wisata hiu paus di Pantai Botubarani. Ketiadaan wisatawan membuat aktivitas wisata Imenjadi lesu. Rintisan Normal Baru pemerintah menjadi harapan kembalinya gairah pariwisata hiu paus di pantai Desa Botubarani. Persiapan dibukanya PPKM (Pemberlakuan Pembatasan Kegiatan Masyarakat) di daerah asal wisatawan dan permudahan perjalan dalam/luar negeri akan disambut dengan penigkatan kualitas dan inovasi wisata hiu paus di Pantai Botubarani. Selain itu, adaptasi wisata di masa pandemi dengan memanfaatkan internet cukup menjanjikan sehingga wisata akan tetap hidup.

Desa inovasi dengan memanfaatkan teknologi dan tren digital terkini menjadi harapan Desa Botubarani agar wisata kembali hidup dengan adaptasi kondisi saat ini. Inovasi siaran langsung bawah air hiu paus yang pertama di dunia ini akan menjadi rintisan yang baik agar level wisata hiu paus di Gorontalo bahkan Indonesia bisa meningkat.

\section{HASIL DAN PEMBAHASAN}

Profil Lokasi Pengembangan Wisata Berbasis IOT

Kegiatan dilakukan di pantai Desa Botubarani, Kecamatan Kabila Bone, Kabupaten Bone Bolango, Provinsi Gorontalo. Pantai Desa Boutobarani telah dikenal sebagai destinasi wisata hiu paus (Rhincodon typus) yang popular di Indonesia sejak Tahun 2016. Kemudahan akses dengan jaminan bertemunya hiu paus yang tinggi, membuat lokasi wisata hiu paus ini menjadi diminati oleh wisatawan lokal, nasional maupun mancanegara. Wisata hiu paus di pantai Desa Botubarani berada dekat dari pusat ibukota provinsi Gorontalo dan hanya berjarak 10 meter dari bibir pantai. Wisata ini sangat ramai dan sangat menyadarkan masyarakat sekitar akan konservasi dan pemanfaatan hiu paus untuk wisata yang berdampak pada peningkatan ekonomi.

\section{Profil Produk Unggulan Daerah}

Hiu paus (Rhincodon typus) merupakan spesies ikan terbesar di dunia yang dapat tumbuh hinggal 18meter bahkan lebih. Spesies ini telah masuk daftar merah terancam punah (Endangerad) oleh IUCN (International Union for Conservation of Nature). Di Indonesia, spesies ini dilindungi penuh melalui Keputusan Menteri Perikanan dan Kelautan No. 18 Tahun 2013. Segala jenis perburuan dan pemanfaatan secara langsung adalah hal yang dilarang.

Keberadaan hiu paus di pantai Desa Botubarani mulai diketahui pada awal Tahun 2016. Hiu paus muncul di belakang pabrik pengepakan vaname ketika pabrik membuang limbah kulit dan kepala udang. Karena fenomena yang sangat jarang terjadi, hiu paus tersebut langsung menjadi destinasi wisata yang ramai. Meskipun pabrik pengepakan berhenti beroperasi Tahun 2017, hiu paus tetap ada dan tetap menjadi destinasi wisata yang menarik (Gambar 1). 


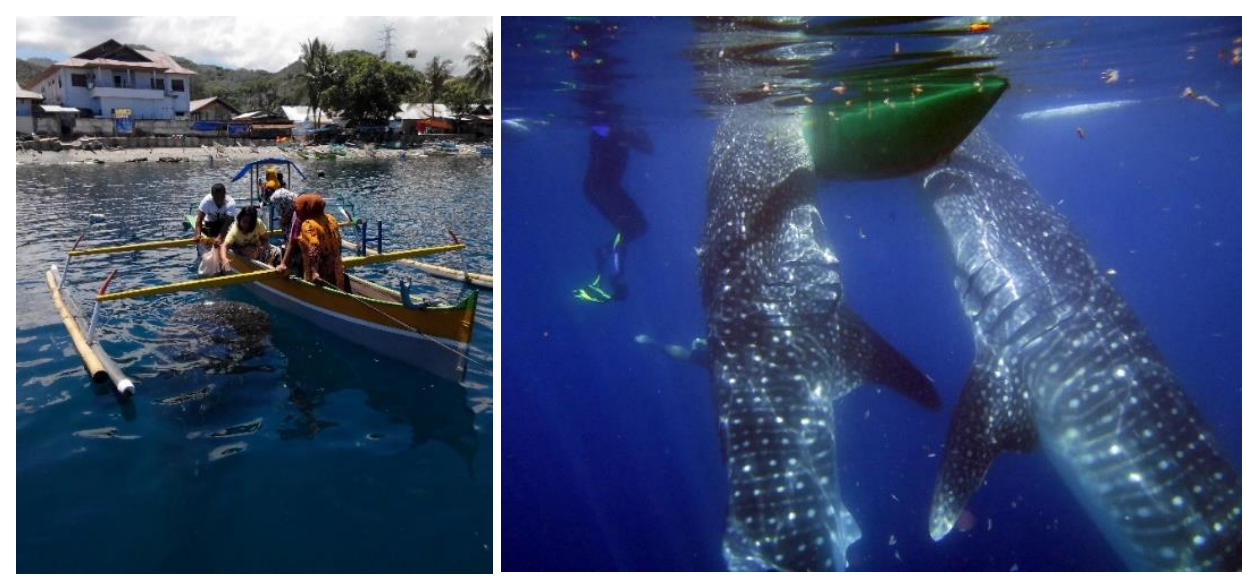

Gambar 1. Hiu paus sebagai destinasi wisata di pantai Desa Botubani, Gorontalo

Pandemi Covid19 memberikan dampak yang signifikan terhadap perkembangan wisata hiu paus di pantai Desa Botubarani. Tren wisatawan asal nasional dan mancanegara yang mendominasi kunjungan berdampak pada aktivitas pariwisata yang lesu. Pemantauan populasi untuk memonitor keberadaan dan kondisi hiu paus yang biasa dilakukan secara berkala pun menjadi jarang dilaksanakan. Wisata hanya mengandalkan kunjungan wisatawan lokal dan luar yang secara kuantitas tergolong kecil. Rintisan Normal Baru pemerintah menjadi harapan kembalinya gairah pariwisata hiu paus di pantai Desa Botubarani. Persiapan dibukanya PPKM (Pemberlakuan Pembatasan Kegiatan Masyarakat) di daerah asal wisatawan dan permudahan perjalan dalam/luar negeri akan disambut dengan penigkatan kualitas dan inovasi wisata hiu paus di Pantai Boubarani. Diharapkan, wisata akan tertarik untuk datang dan kembali ke Gorontalo.

\section{Profil Teknologi dan Inovasi}

Pengembangan wisata hiu paus di pantai Botubarani berbasis teknologi dan inovasi mendesak dilakukan sebagai penyesuaian terhadap perkembangan zaman dan adaptasi pandemi COVID19. Siaran langsung jelajah virtual bawah air dengan objek hiu paus secara berkala di alam liar belum pernah dilakukan di dunia. Pemanfaatan televisi sirkuit tertutup atau closed circuit television (CCTV) bawah air yang dapat diakses di darat dan terintegrasi dengan internet memungkinkan hiu paus di Pantai Botubarani dapat dinikmati oleh siapapun dan dimanapun.

Desa dan masyarakat di Pantai Botubarani dapat menerima masukan dari perkembangan wisata yang berlangsung dari wisatawan yang datang maupun secara virtual. Wisatawan juga mungkin akan tertarik untuk datang setelah melihat siaran langsung hiu paus di pantai Desa Botubarani. Selain itu, perekaman video secara langsung hiu paus juga dapat dimanfaatkan oleh pihak intelektual, pemerintah dan industri sebagai bagian dari kolaborasi triple helix (Gambar 2). 


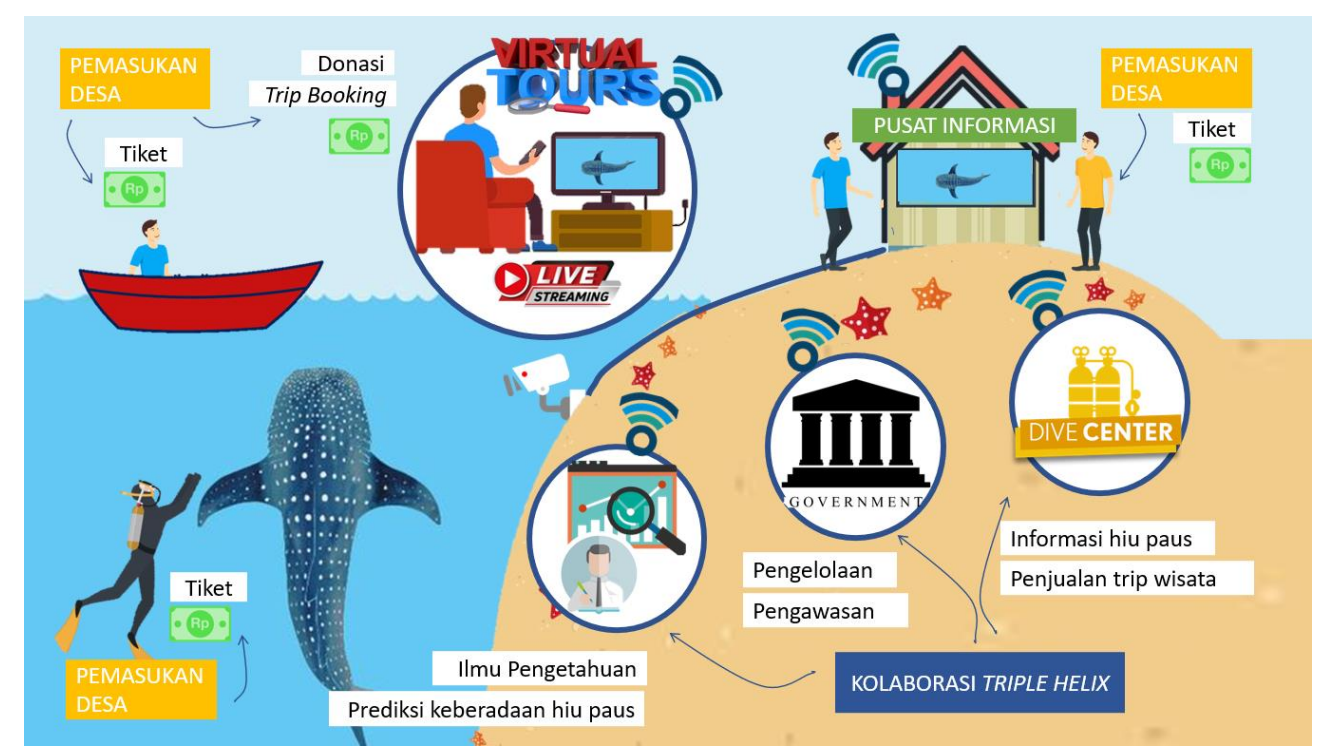

Gambar 2. Ilustrasi inovasi siaran langsung jelajah virtual bawah air hiu paus

Teknologi dan Inovasi dari siaran langsung jelajah virtual bawah air dengan objek hiu paus secara berkala di alam liar yang pertama di dunia dijelaskan sebagai berikut;

1. Pemasangan kamera CCTV di bawah air dengan kedalaman \pm 5 meter yang terhubung dengan televisi 60" di pusat informasi wisata hiu paus di pantai Desa Botubarani, Gorontalo. Wisatawan yang datang dapat melihat hiu paus yang ada saat itu dan mungkin akan berinteraksi langsung dari atas kapal, snorkeling maupun menyelam. Desa dalam hal ini mendapatkan pemasukan melalui jasa wisata.

2. CCTV yang ditampilkan di televisi diintegrasikan dengan jaringan internet sehingga dapat diakses pada laman/website desa yang akan dikembangkan. Masyarakat Indonesia maupun luar negeri dapat melihat siaran langsung bawah air hiu paus di pantai Desa Botubarani dengan perangkat elektronik gawai masing-masing. Wisatawan online tersebut dapat memberikan donasi untuk ikut jelajah virtual dan memesan wisata melalui website dimasa mendatang yang menjadi pemasukan desa. Dengan demikian, pemasaran wisata hiu paus juga dapat berkembang dan tersebar luas.

\section{Analisis Kolaborasi triple helix}

Kolaborasi triple helix antara intelektual, pemerintahan dan industri bisnis wisata juga dapat berjalan dan saling terintegrasi satu sama lain sebagai berikut;

1. Intelektual/akademisi, dapat memanfaatkan CCTV sebagai data pemantauan populasi hiu paus seperti, photo identification, jumlah, pergerakan, estimasi ukuran dan prediksi pola kedatangannya di Pantai Botubarani. Informasi tersebut menjadi ilmu pengetahuan yang dapat membatu dalam strategi pengelolaan wisata dan konservasinya bagi pemerintah dan usaha pariwisata.

2. Pemerintah, dapat memanfaatkan CCTV sebagai media menjalankan fungsi dalam pengelolaan dan pengawasan. Selain itu, melalui hasil penelitian dari akademisi pemerintah juga dapat membuat evaluasi dan strategi pengembangan wisata.

3. Bisnis wisata, dapat memanfaatkan CCTV sebagai informasi keberadaan hiu paus dan media promosi kepada para wisatawan untuk datang. Hasil penelitian akademisi juga membantu usaha wisata dalam memilih waktu terbaik membuka perjalanan wisata hiu paus. Pengelolaan pemerintah 


\section{KESIMPULAN DAN SARAN}

Pengembangan wisata hiu paus berbasis iot (internet of things) melalui siaran langsung jelajah virtual hiu paus di alam liar di pantai Desa Botubarani, Kabila Bone, Bone Bolango, Gorontalo sangat tepat untuk dikembangkan. Karakteristik hiu paus yang tidak agresif dan lokasi penelitian yang memungkinkan dilakukan pemasangan instalasi cctv bawah air menjadikan faktor yang sangat mendukung terlaksananya siaran langsung di bawah air. Pengembangan wisata hiu paus berbasis iot tersebut sangat berpotensi dalam menarik minat wisatawan dalam era normal baru, baik secara daring maupun luring.

\section{UCAPAN TERIMA KASIH}

Penulis mengucapkan terima kasih kepada Badan Riset dan Inovasi Nasional (BRIN) melalui program Bantuan Pemerintah berupa Desa Berinovasi Tahun 2021. Selain itu, penulis juga mengucapkan terima kasih kepada Dinas Pariwisata Kabupaten Bone Bolango Gorontalo, Pemerintah Desa Botubarani Kabupaten Bone Bolango Gorontalo dan Yayasan Ekonomi dan Keanekaragaman Hayati (YEKHALI) atas dukungan yang diberikan.

\section{DAFTAR PUSTAKA}

Colman JG. 1997. A review of the biology and ecology of the whale shark. J Fish Biol. 51:1219-1234. Compagno LV. 2001. Sharks of the world: an annotated and illustrated catalogue of shark species known to date. Volume 2: Bullhead, mackerel and carpet sharks (Heterodontiformes, Lamniformes and Orectolobiformes). Rome (Italy): FAO.

Himawan MR, Tania C, Noor BA, Wijonarno A, Subhan B, Madduppa H. 2015. Sex and size range composition of whale shark (Rhincodon typus) and their sighting behaviour in relation with fishermen lift-net within Cenderawasih Bay National Park, Indonesia. AACL Bioflux 8 (2): 123133. 